\title{
Best Supportive Care from the Conservative/ Non-Surgical Perspective and lts Costs in the Treatment of Patients with Advanced Medullary Thyroid Cancer: Results of a Delphi Panel
}

\author{
Michael C. Kreissl ${ }^{a, b} \quad$ Christian Jacob ${ }^{c}$ Dagmar Führer ${ }^{d}$ Wolfram Karges ${ }^{e}$ \\ Markus Luster ${ }^{f} \quad$ Michael P. Lux ${ }^{g} \quad$ Klaus Mann $^{d}$ Thomas Mittendorf ${ }^{c}$ \\ Matthias Schott ${ }^{\mathrm{h}} \quad$ Christine Spitzweg $^{\mathrm{i}}$ Hans-Joachim Schmoll ${ }^{\mathrm{k}}$
}

${ }^{a}$ Department of Nuclear Medicine, University Hospital of Wuerzburg; ${ }^{b}$ Department of Nuclear Medicine, Central Hospital of Augsburg; ${ }^{\mathrm{c}}$ Herescon $\mathrm{GmbH}$, Hanover; ${ }^{\mathrm{d} D e p a r t m e n t}$ of Endocrinology and Metabolic Disorders, Essen University Hospital; ${ }^{\mathrm{e} D i v i s i o n}$ of Endocrinology and Diabetes, RWTH Aachen University Hospital; 'Department of Nuclear Medicine, University Hospital of Ulm; ${ }^{9}$ Frauenklinik, University Hospital of Erlangen, Friedrich Alexander University, Erlangen; 'Division of Endocrinology, Department of Endocrinology and Diabetes, Duesseldorf University Hospital; 'Department of Internal Medicine II, University Hospital of Munich, Ludwig Maximilians University Munich; 'University Hospital of Halle (Saale), Germany

\section{Keywords}

Medullary thyroid cancer - Delphi panel · Best supportive care $\cdot$ Costs $\cdot$ Germany $\cdot$ Health economics

\section{Summary}

Background: Medullary thyroid cancer (MTC) is a rare tumor entity. The contents of best supportive care (BSC) have not been defined in advanced MTC. The objective of this work is to describe the epidemiology, the treatment patterns with respect to symptom management, as well as palliative treatment and associated costs. Method: A Delphi panel with 9 clinical experts experienced in treating MTC was conducted to obtain details on the epidemiology of MTC and to gain insights into the therapeutic options considered for BSC in advanced MTC in Germany. Unit costs were applied to the described resources from the perspective of the German National Healthcare System in 2011. Results: The annual incidence of MTC in Germany was estimated at about $220.32 \%$ of all patients were estimated to have aggressive/symptomatic MTC, with an estimated mean survival of 36.7 months (median: 36 months). The core element of BSC is relief of symptoms to maintain quality of life. The total mean cost of BSC per patient/year was estimated at $€ 9,248$, lifetime cost at $€ 28,283$. Conclusion: There was consistent agreement within the panel on the epidemiology of MTC and on the structure of the provided therapeutic measures for BSC in advanced MTC, also defining the management of symptoms as a crucial goal of treatment.

\section{KARGER}

Fax +497614520714

Information@Karger.com

www.karger.com (c) 2014 S. Karger GmbH, Freiburg

2296-5270/14/0376-0316\$39.50/0

Accessible online at:

www.karger.com/ort

\section{Introduction}

Medullary thyroid cancer (MTC) is a rare tumor entity (5$10 \%$ of all thyroid cancers) $[1,2]$. It has a variable course and may result in a variety of different symptoms, also caused by abnormal hormone production. For the treatment of patients with aggressive, metastatic and symptomatic MTC not amenable to surgery, no systemic therapy was approved in Germany until early 2012. For patients affected by this tumor, only palliative therapies - most of them off-label - and best supportive care (BSC) were available.

Currently, the structure of health services provided to patients under BSC in this population is not defined. Moreover, there are no recommendations as to which BSC measures should be considered in MTC patients. Different definitions of BSC are available in the literature. According to the European Organisation for Research and Treatment of Cancer, BSC is defined as 'supportive care with a multi-professional attention to the individual's overall physical, psychosocial, spiritual and cultural needs, and should be available at all stages of the illness, for patients of all ages, and regardless of the current intention of any anti-cancer treatment' [3].

In the existing literature, no common consensus has been reached so far. According to Salzwimmer [4], BSC includes the following general aspects:

- improvement of the prerequisites for performing oncological therapies

- reduction of the incidence of side effects of cytotoxic therapies

- maintenance or improvement of the patients' quality of life 
- alleviation of tumor-associated symptoms

- prognostic improvement of the treatment results

As of today, the discussion is still ongoing whether systemic therapies form a part of BSC. Since until recently no standard therapy existed in MTC, all potentially feasible palliative and symptom management-oriented therapeutic measures can be defined as part of a BSC concept. It has to be noted that, in advanced MTC, symptoms resulting from excessive hormone production, e.g. diarrhea, also need to be addressed by appropriate therapies in order to maintain quality of life.

An expert panel approach was chosen to identify therapies and measures that are deemed part of BSC in MTC patients in Germany. Another objective of this study was to assess the costs of BSC in advanced MTC to form a database for future health economic research.

\section{Methods}

\section{Delphi Panel}

To identify the various components of BSC for MTC patients, the Delphi method was applied. This systematic, consensus-oriented, multilevel interview technique aims to combine the expertise and knowledge of individual participants to generate consensus statements on previously defined study subjects $[5,6]$. The process is divided into successive rounds of questioning. In each round, the participants are interviewed individually and independently. Following each round, the survey responses are aggregated, condensed and again presented to the participants. During this phase, the participants are invited to review and comment on their previous answers in light of the summarized responses. The different steps of the Delphi process are repeated until maximum agreement is achieved. All participants remain anonymous until the end of the process.

In the present study, the questionnaire-based Delphi panel was held in 2 rounds from November 2011 to January 2012, with 9 clinical experts in endocrinology and/or the treatment of MTC. The Delphi panel consisted of 6 endocrinologists, 2 nuclear medicine specialists, and 1 general oncologist. All participants are involved in the treatment of MTC on an academic and patient level, covering 7 university hospitals in Germany and taking care of approximately 132 new MTC cases (of all tumor stages) per year. The Delphi panel was accompanied by an independent methodological expert.

In the first round, the experts were asked about the different areas of therapy in MTC. The topics of the questionnaire covered the epidemiology, the treatment options in a palliative setting, the treatment options for symptomatic BSC, and a comparison of different treatment options. Responses were given via e-mail, fax, or by post.

During the second round, the participants were asked to comment on the mean results and a summary of free-text questions, to determine the final results. A predefined consensus criterion of at least $75 \%$ agreement on each topic was already reached after the second round of questioning. Further comments and divergent opinions were documented.

\section{Costs}

Cost data were obtained from different sources. Costs for medication and concomitantly used drugs are based on the ArzneiverordnungsReport 2011 [7], which is the most comprehensive (annual) report on medication costs and prescription patterns in ambulatory care in Germany. Costs in this area are expressed in terms of the defined daily dose (DDD) [8]. The costs of occupational therapy and physiotherapy were obtained from the official reimbursement catalogue (Heilmittel- katalog) [9], which provides an overview of all reimbursable remedies available within the German statutory health insurance. Costs for enteral nutrition, palliative surgery, psychotherapy, and oxygen support measures are based on the current German Uniform Valuation Scheme (Gebührenordnung Einheitlicher Bewertungsmaßstab: EBM 2011) [10] for additional services provided in the ambulatory setting, the current German diagnosis-related groups (DRG) catalogue (2012), the Lauer-Taxe (German Red Book), and on manufacturer prices for medical devices as applicable.

Direct non-medical costs (e.g. costs for transportation to a hospital or outpatient clinic), indirect costs, and intangible costs due to impacts on quality of life (e.g. pain or distress) were not included in the analyses. Furthermore, out-of-pocket costs of patients were not integrated.

To calculate the average costs of BSC in advanced MTC, all cost elements per DDD were weighted by the proportion of their use in BSC as reported by the Delphi panel. All costs were calculated from the perspective of a German healthcare insurance.

\section{Results}

\section{Epidemiology}

On the basis of the results of the panel, the annual incidence of MTC in Germany is estimated at about 220 cases. According to the panel, up to $32 \%$ of the patients diagnosed with MTC have an aggressive and symptomatic tumor (71 cases), which is non-resectable, locally advanced, or metastasized. These patients have a mean life expectancy of 36.7 months (median: 36 months). In the end stage of the disease, most of these patients $(64 \%)$ are taken care of at home, either by ambulatory care and/or by caregivers. About $29 \%$ of the final-stage patients are treated in an inpatient setting, with $20 \%$ in an internal medicine ward, $9 \%$ in a palliative care unit, and $8 \%$ in a hospice. The end stage of the disease lasts for around 15 weeks, on average.

\section{Treatment Options in a Palliative Setting}

According to the statements of the panel, BSC in nonresectable, locally advanced or metastasized MTC mainly focuses on the relief of symptoms associated with the tumor or its metastases. Since even in an advanced MTC stage overall survival is fairly long compared to other cancers, this approach is of paramount importance to maintain the quality of life. Special emphasis should be put on maintaining the mobility of the patients and providing nutritional support. Other measures are pain therapy, antidiarrheal treatment, prevention of the wasting syndrome, skin care, and - in patients with bone metastases - administration of bisphosphonates. Local radiotherapy may be considered in cases with bones metastases and locally advanced disease with spread to the mediastinum or developed brain metastases. Hepatic metastases may be treated using transarterial chemoembolization (TACE).

Off-label treatment with a tyrosine kinase inhibitor and inclusion in a clinical trial were also reported as options besides BSC. According to the panel, $18 \%$ of the patients with advanced disease receive chemotherapy, $29 \%$ are treated with local radiotherapy, $54 \%$ are enrolled in clinical trials 
evaluating tyrosine kinase inhibitors, and $22 \%$ are treated using other therapies, e.g. peptide receptor radionuclide therapy. $3.5 \%$ refuse any kind of treatment besides symptomatic therapy.

\section{Costs of Treatment}

The Delphi panel defined a need for drugs, symptomatic treatment, and other healthcare measures as described in tables 1 and 2 . The highest percentage of use (56.7\%) was attributed to antidiarrheals needed to treat hormone-induced diarrhea, which can be observed in most cases of advanced MTC. Some of the patients also require additional treatment for functional gastrointestinal disorders, e.g. nausea $(17.2 \%)$; some also require special enteral nutrition (16.1\%), which is cost intensive. As in other advanced tumors, bone metastases

Table 1. Prescription patterns and services provided in BSC in advanced MTC

\begin{tabular}{|c|c|c|c|c|}
\hline \multirow{2}{*}{ Medications/BSC measures } & \multicolumn{4}{|c|}{ Percentage of use } \\
\hline & Mean & Median & Minimum & Maximum \\
\hline \multicolumn{5}{|l|}{ Medications } \\
\hline Antidiarrheals & 56.67 & 50 & 10 & 100 \\
\hline Analgesics (excluding opiates) & 39.44 & 40 & 5 & 80 \\
\hline Opiates & 31.11 & 20 & 5 & 90 \\
\hline Bisphosphonates & 27.78 & 20 & 10 & 80 \\
\hline Antiemetics & 21.67 & 10 & 0 & 70 \\
\hline Other medications targeting functional gastrointestinal disorders & 17.22 & 0 & 0 & 100 \\
\hline Antidepressants & 9.44 & 10 & 0 & 20 \\
\hline Sedatives & 8.11 & 6.5 & 0 & 30 \\
\hline Diuretics & 5.63 & 0 & 0 & 30 \\
\hline Laxatives & 5.56 & 0 & 0 & 30 \\
\hline Antiepileptics & 4.22 & 5 & 0 & 10 \\
\hline Neuroleptics & 3.11 & 0 & 0 & 20 \\
\hline Immunostimulants & 0.89 & 0 & 0 & 5 \\
\hline \multicolumn{5}{|l|}{ Other services } \\
\hline Palliative radiotherapy & 28.75 & 20 & 0 & 70 \\
\hline Enteral nutrition & 16.11 & 10 & 0 & 80 \\
\hline Occupational therapy & 15.33 & 3 & 0 & 70 \\
\hline Psychotherapy & 11.11 & 10 & 0 & 20 \\
\hline Palliative surgery & 10.33 & 10 & 0 & 30 \\
\hline Oxygen support & 2.78 & 0 & 0 & 10 \\
\hline
\end{tabular}

$\mathrm{BSC}=$ Best supportive care.

Table 2. Costs of BSC in advanced MTC

\begin{tabular}{|c|c|c|c|c|c|}
\hline \multirow[b]{2}{*}{ Medications/BSC measures } & \multirow[b]{2}{*}{ Percentage of use } & \multicolumn{4}{|l|}{ Weighted cost } \\
\hline & & $\begin{array}{l}\text { Based on DDD } \\
(€)\end{array}$ & Per day, $€$ & $\begin{array}{l}\text { Per month } \\
\text { (30 days), € }\end{array}$ & $\begin{array}{l}\text { Per year } \\
\text { (365 days), } €\end{array}$ \\
\hline \multicolumn{6}{|l|}{ Medications } \\
\hline Antidiarrheals & 56.67 & 2.30 & 1.30 & 39.10 & 475.74 \\
\hline Analgesics (excluding opiates) & 39.44 & 1.45 & 0.57 & 17.16 & 208.74 \\
\hline Opiates & 31.11 & 3.06 & 0.95 & 28.58 & 347.68 \\
\hline Bisphosphonates & 27.78 & 12.97 & 3.60 & 108.10 & $1,315.19$ \\
\hline Antithrombotics & 21.11 & 0.68 & 0.14 & 4.32 & 52.51 \\
\hline $\begin{array}{l}\text { Other medications targeting functional } \\
\text { gastrointestinal disorders }\end{array}$ & 17.22 & 0.49 & 0.08 & 2.51 & 30.56 \\
\hline Antidepressants & 9.44 & 0.69 & 0.07 & 1.95 & 23.77 \\
\hline Sedatives & 8.11 & 0.67 & 0.05 & 1.63 & 19.84 \\
\hline Diuretics & 5.63 & 0.20 & 0.01 & 0.33 & 4.01 \\
\hline Laxatives & 5.56 & 0.76 & 0.04 & 1.27 & 15.45 \\
\hline Antiepileptics & 4.22 & 2.58 & 0.11 & 3.26 & 39.70 \\
\hline Immunostimulants & 0.89 & 66.33 & 0.59 & 17.71 & 215.48 \\
\hline \multicolumn{6}{|l|}{ Other services } \\
\hline Physiotherapy & 29.22 & 3.94 & 1.15 & 34.54 & 420.21 \\
\hline Palliative radiotherapy & 28.75 & 3.65 & 1.05 & 31.48 & 383.02 \\
\hline Enteral nutrition & 16.11 & 66.57 & 10.72 & 321.73 & $3,914.42$ \\
\hline Occupational therapy & 15.33 & 5.00 & 0.77 & 23.00 & 279.77 \\
\hline Psychotherapy & 11.11 & 2.41 & 0.27 & 8.02 & 97.56 \\
\hline Palliative surgery & 10.33 & 21.56 & 2.23 & 66.80 & 812.76 \\
\hline Oxygen support & 2.78 & 41.02 & 1.14 & 34.21 & 416.23 \\
\hline Total costs, $€$ & & & 25.32 & 760.15 & $9,248.49$ \\
\hline
\end{tabular}


occur frequently in MTC. In order to prevent fractures and reduce pain, bisphosphonates are commonly used $(27.8 \%)$ and account for a substantial fraction of the overall cost of BSC in advanced MTC.

In addition, analgetics (excluding opiates) (39.4\%) and opiates $(31.1 \%)$ are frequently applied. Patients occasionally require palliative radiotherapy due to progressive cervical tumors and painful metastases in bones or other sites $(28.8 \%)$. Palliative surgery, especially to ensure airway patency but also to enable enteral nourishment, is necessary in $10.3 \%$ of the patients. According to the results of the panel, $18.3 \%$ of the patients receive a treatment by chemotherapy (non-curative in intention).

\section{Total Costs per Patient and Year}

The total mean costs for BSC per patient with advanced MTC were calculated on a per-month and per-year basis and are estimated to be $€ 760 /$ month and $€ 9,248$ /year, respectively. Assuming a mean survival of 36.7 months, lifetime costs amount to $€ 28,283$.

\section{Discussion}

This study assessed data on the epidemiology, treatment patterns in symptom management, palliative treatment, and the costs associated with BSC in advanced MTC in Germany.

It was shown that German experts have a consensual understanding of advanced MTC in terms of its epidemiology. The annual incidence of MTC was estimated at about 220. This number is in line with previously published data stating a fraction of 5-10\% MTCs among all thyroid cancers [11, 12], which are estimated to have an annual incidence of 5,300 in Germany [13]. However, in other publications, the fraction of MTC is only 1-3\% [14]. According to the expert panel, up to $32 \%$ of the patients diagnosed with MTC have an aggressive and symptomatic tumor, which can be non-resectable, locally advanced, or metastasized. Exact data on this topic are lacking, but a German survey found $45 \%$ of patients in stage III and $8 \%$ in stage IV, at initial presentation (per definition, all of these patients were advanced and/or metastasized but not necessarily symptomatic or progressive) [15].

In general, the suggestions of the panel were in line with published guidelines for treating MTC from the American Thyroid Association (ATA) [16] and the European Society for Medical Oncology (ESMO) [17] and with the recently published guidelines of the European Thyroid Association for metastatic MTC [18]. However, treatment of patients in advanced stages only constitutes a small fraction of these guidelines, and the level of evidence for specific recommendations on single measures is usually not very high. Both guidelines advocate the inclusion of patients in clinical trials with new targeted therapies, which was also suggested by the panel experts. Since the participation in trials is not always possible and off-label use of tyrosine kinase inhibitors is legally problematic and not commonly covered by health insurances, these two options were not addressed in the calculation of costs for BSC.

Approximately one-third of the final-stage patients are treated as inpatients. These services in Germany are reimbursed via a DRG system for hospital stays and on a daily basis for hospice stays. Besides the included BSC items, additional costs for hospital or hospice stays are not included in the calculation of BSC costs. Therefore, the estimated costs of $€ 9,248 /$ year most likely represent an underestimation.

There might be additional costs associated with the treatment of MTC patients due to regular physician contacts, medical examinations, and laboratory tests. These costs are not included in the calculation of BSC costs because of the structure of the German reimbursement system for outpatients. Services are covered by a more or less flat quarterly payment, which includes services in the ambulatory setting regardless of the quantity of services provided. By taking the perspective of the statutory health insurance, no accurate estimation of the fraction of services due to BSC is possible, and therefore no precise attribution of costs is feasible. Although the quarterly fees vary in different regions in Germany, they will rarely exceed $€ 100$ /patient from the perspective of the health insurance. In case of a private health insurance, the additional cost for these services might be higher because every physician contact is reimbursed separately instead of being covered by a quarterly fee.

Not many studies have been published assessing the costs of BSC in other tumor entities. Usually, health economic evaluations or cost effectiveness studies tend to focus more on new systemic therapeutic options and not on BSC.

Non-small-cell lung cancer (NSCLC) is the malignancy with the most comprehensive data in this respect. Araujo et al. [19] calculated $€ 16,112$ for a 2 -year period of BSC ( $€ 8,056$ / year) using a cost-utility model in 2008. In contrast, Isla et al. [20] in 2011 applied a Delphi panel and obtained $€ 3,410$ as lifetime cost (median 3.5 months) of BSC in advanced NSCLC in Spain. Navaratam et al. [21] performed a database analysis including chart reviews and obtained a figure of \$CAN 8,654 as total expenses for 1 period of BSC (median 13.8 weeks). There are also 2 studies using a Markov model, published in 2008 and 2010, on the lifetime total cost in hepatocellular cancer, yielding costs of \$CAN 10,376 $\pm 1,649$ and \$US 7,804 $\pm 1,349$, respectively [22, 23]. In 2008, Purmonen et al. [24] calculated the 1-year expenses for BSC in metastatic renal cell carcinoma to be $€ 5,543$, using a probabilistic decision-analytic model. A fairly high amount for 1 year of BSC in metastatic breast cancer of \$US 23,379 was found by Sorensen et al. [25] using a cost-of-illness model.

Costs for the provision of healthcare have been increasing for years. Germany is one of the countries with the highest spending on healthcare [26, 27], with drug costs having risen from $€ 19.2$ billion in 1999 to $€ 32.4$ billion in 2009 [28]. 
In order to meet this challenge in the longer term, an additional dimension aside from clinical efficacy is increasingly being incorporated into medical decision-making: the assessment of costs relative to benefits by using health economic decision-making models. In Germany, following the latest healthcare reform (the Drug Market Reform Act, Arzneimittelmarktneuordnungsgesetz, AMNOG), a structured assessment of the additional clinical benefit of a new drug is carried out by the Federal Joint Committee (Gemeinsamer Bundesausschuss, G-BA) [29]. Hence, there is an urgent need for the definition and description of existing care patterns (e.g. BSC) in different oncological indications and for the evaluation of costs in these different treatment settings, in order to build a set of baseline data for future health economic studies for new treatment options in combinations or also versus BSC. The results of this Delphi consensus are one important step to reach these goals.

\section{Limitations}

A limitation of this study is the lack of the surgical perspective. The majority of MTC patients in an early state of the disease are seen by a surgeon, who plays a major role in the initial therapy, staging, and decisions on further treatment steps. Thus, the estimation of incidence, and likewise the proportion of advanced cases, might be underestimated. Also, the role of palliative surgery in order to relieve pain and safeguard airways and oral feeding might be more prominent from a surgical perspective.

As in many oncologic indications and also as a limitation in this study, the terms 'symptomatic' and 'aggressive' in this survey were not further specified and, hence, may have been defined in different ways by the experts. Commonly, 'symptomatic' refers to a patient being affected by the tumor or its therapy. But, depending on how thoroughly a treating physician investigates a patient, tumor-associated symptoms may be found in almost all patients. Similarly, 'aggressive' is not defined at all. Even metastasized MTC has a 10-year survival rate of $40 \%$ according to the Surveillance, Epidemiology and End Results (SEER) registry $(\mathrm{n}=1,252)$. However, $40 \%$ of the patients with metastatic disease die within 2 years [30].

Use of the Delphi method is associated with some limitations that might also play a role in other interview techniques. A common point of criticism circles around the selection of the participating experts. There are no binding rules on how to identify and select the relevant experts in a field of interest. Thus, the initiator of a Delphi panel has to ensure a thorough selection process of the panelists [31]. In the present study, the identification of relevant experts was based on an academic background in the therapy of MTC. 13 experts were invited to the panel, of which 9 finally took part in the survey. As MTC is a rare condition, only a very limited number of clinicians will take care of these patients in Germany. Hence, reflecting prevalence numbers for this indication with the number of patients treated by the panel members, it should be fair to state that the panel is representative.

At the time of the Delphi panel, no systemic therapy was approved for the treatment of MTC. With the approval of vandetanib in February 2012 in Germany, a tyrosine kinase inhibitor became available for the treatment of advanced MTC. Considering this new treatment option, the results of the panel and BSC may be different in the future. This limitation also applies to the calculated costs, which may change with this treatment option available.

\section{Conclusions}

There was consistent agreement within the panel on the prevalence and the structure of treatment options within BSC of patients with advanced MTC. Management of advanced MTC is performed in accordance with published guidelines; special emphasis is put on the treatment and prevention of tumor-related symptoms. Substantial costs occur for BSC from the perspective of the healthcare system; these costs are comparable to those for BSC in other tumor entities. Moreover, the results of this study can be used as a basis for future health economic evaluations in this setting.

\section{Disclosure Statement}

The Delphi panel was funded by a grant from AstraZeneca GmbH. M.C.K., D.F., W.K., M.L., M.P.L., K.M., M.S., C.S., and H.J.S. received compensation for their participation in the Delphi panel, but not for the work related to this publication. With the exception of M.P.L., who acted as expert in cost calculation, all others acted as clinical experts for MTC. C.J. and T.M. are employed by Herescon GmbH, which received consulting fees for the conduct of the Delphi panel from AstraZeneca GmbH.

\section{References}

1 Orlandi F, Caraci P, Mussa A, Saggiorato E, Pancani G, Angeli A: Treatment of medullary thyroid carcinoma: an update. Endocr Relat Cancer 2001;8:135-147.

2 Schlumberger M, Carlomagno F, Baudin E, Bidart JM, Santoro M: New therapeutic approaches to treat medullary thyroid carcinoma. Nat Clin Pract Endocrinol Metab 2008;4:22-32.
3 Ahmedzai SH, Lubbe A, Van den Eynden B: Towards a European standard for supportive care of cancer patients. A coordinated activity funded by DGV. Final report for EC on behalf of the EORTC Pain and Symptom Control Task Force. pp 1-25, 2001.

4 Salzwimmer M: [Best supportive care in head and neck cancer]. Wien Med Wochenschr 2008;158:278282.
5 Brown BB: Delphi process: a methodology used for the elicitation of opinions of experts. www.rand.org/pubs/papers/2006/P3925.pdf, 1968.

6 Kelly C, Jorm A, Kitchener B: Development of mental health first aid guidelines on how a member of the public can support a person affected by a traumatic event: a Delphi study. BMC Psychiatry 2010;10:49. 
> Arzneiverordnungs-Report 2011. Berlin, Heidelberg, Springer, 2011

8 WHO Collaborating Centre for Drug Statistics Methodology. www.whocc.no/ddd/definition_and general_considera/, 2012

9 Heilmittelkatalog. IntelliMed GmbH, www.heilmittelkatalog.de/hmkonline.html, 2011.

10 Kassenärztliche Bundesvereinigung: Einheitlicher Bewertungsmaßstab (EBM). www.kbv.de/8156. html;http://www.sindbad-mds.de/infomed/sindbad. nsf/0/191df9e3c108dbdfc1257975004ce15f/\$FILE/ EBM_Q-I_2012.pdf, 2012.

11 Raue F, Frank-Raue K: Multiple endocrine neoplasia type 2: 2007 update. Horm Res 2007;68 (suppl 5):101-104

12 Reiners C, Dietlein M, Luster M: [Malignant goiter - thyroid cancer]. Dtsch Med Wochenschr 2008, 133:2215-2228.

13 Krebs in Deutschland 2005/2006. Häufigkeiten und Trends, ed 7. Berlin, Robert Koch-Institut und die Gesellschaft der epidemiologischen Krebsregister in Deutschland e.V., 2010.

14 Schmid KW: Pathogenese, Klassifikation und Histologie von Schilddrüsenkarzinomen. Der Onkologe 2010;16:644-656.

15 Raue F: German medullary thyroid carcinoma/ multiple endocrine neoplasia registry. German MTC/MEN Study Group. Medullary Thyroid Carcinoma/Multiple Endocrine Neoplasia Type 2. Langenbecks Arch Surg 1998;383:334-336.

17 Pacini F, Castagna MG, Brilli L, Pentheroudakis G: Thyroid cancer: ESMO clinical practice guidelines for diagnosis, treatment and follow-up. Ann Oncol. 2010;21(suppl 5):v214-v219.

18 Schlumberger M, Bastholt L, Dralle H, Jarzab B, Pacini F, Smit JWA; The European Thyroid Association Task Force: 2012 European Thyroid Association guidelines for metastatic medullary thyroid cancer. Eur Thyroid J 2012;1:5-14.

19 Araujo A, Parente B, Sotto-Mayor R, Teixeira E, Almodovar T, Barata F, Queiroga H, Pereira C, Pereira H, Negreiro F, Silva C: An economic analysis of erlotinib, docetaxel, pemetrexed and best supportive care as second or third line treatment of non-small cell lung cancer. Rev Port Pneumol 2008;14:803-827.

20 Isla D, Gonzalez-Rojas N, Nieves D, Brosa M, Finnern HW: Treatment patterns, use of resources, and costs of advanced non-small-cell lung cancer patients in Spain: results from a Delphi panel. Clin Transl Oncol 2011;13:460-471.

-21 Navaratam S, Kliewer EV, Butler J, Demers AA, Musto G, Badiani K: Population-based patterns and cost of metastatic non-small cell lung cancer after completion of chemotherapy until death. Lung Cancer 2010;70:110-115.

22 Carr BI, Carroll S, Muszbek N, Gondek K: Economic evaluation of sorafenib in unresectable hepatocellular carcinoma. J Gastroenterol Hepatol 2010;25:1739-1746.

16 Kloos RT, Eng C, Evans DB, Francis GL, Gagel RF, Gharib H, Moley JF, Pacini F, Ringel MD, Schlumberger M, Wells SA Jr: Medullary thyroid cancer: management guidelines of the American Thyroid Association. Thyroid 2009, 19:565-612.
24 Purmonen T, Martikainen JA, Soini EJ, Kataja V, Vuorinen RL, Kellokumpu-Lehtinen PL: Economic evaluation of sunitinib malate in secondline treatment of metastatic renal cell carcinoma in Finland. Clin Ther 2008;30:382-392.

25 Sorensen SV, Goh JW, Pan F, Chen C, Yardley D, Martin M, Knopf K, Benedict A, Giorgetti C, Iyer S: Incidence-based cost-of-illness model for metastatic breast cancer in the United States. Int J Technol Assess Health Care 2012;28:12-21.

26 Porzsolt F: Klinische Ökonomik. Die ökonomische Bewertung von Gesundheitsleistungen aus der Sicht des Patienten; in Porzsolt F, Williams AR (eds): Klinische Ökonomik. Effektivität und Effizienz von Gesundheitsleistungen. Landsberg, ecomed, 2003, pp 17-40.

27 Lux MP, Beckmann MW: Klinische Ökonomie in der gynäkologischen Onkologie. FHA 2008;2: 35-41.

28 Bundesministerium für Gesundheit: Infografiken zum Arzneimittelmarktneuordnungsgesetz. www.bmg.bund.de/krankenversicherung/ arzneimittelversorgung/amnog.html, 2011.

29 Bundesministerium für Gesundheit: Gesetz zur Neuordnung des Arzneimittelmarktes (AMNOG). www.bmg.bund.de/krankenversicherung/ arzneimittelversorgung/amnog/amnog.html, 2010.

30 Roman S, Lin R, Sosa JA: Prognosis of medullary thyroid carcinoma: demographic, clinical, and pathologic predictors of survival in 1252 cases. Cancer 2006;107:2134-2142.

31 Sackman H: Delphi assessment: expert opinion, forecasting, and group process. United States Air Force Project RAND, R-1283-PR, 1974. 